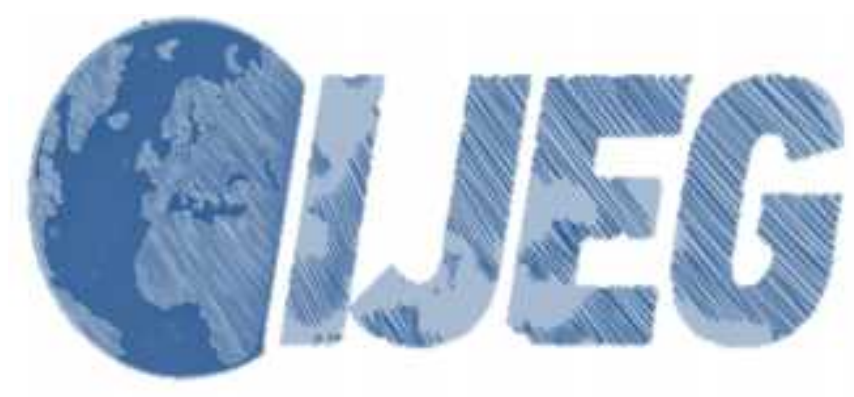

International Journal of Engineering and Geosciences (IJEG),

Vol; 3; Issue; 3, pp. 087-097, October, 2018, ISSN 2548-0960, Turkey,

DOI: 10.26833 ijeg.412222

\title{
DESIGNING A SUSTAINABLE RANGELAND INFORMATION SYSTEM FOR TURKEY
}

\author{
Akar, A., ${ }^{1 *}$ Gokalp, E., ${ }^{2}$ \\ ${ }^{1}$ Erzincan University, Vocational School Land Registry and Cadastre, 24100 Erzincan, Turkey \\ (alperakar24@gmail.com); \\ ${ }^{2}$ Karadeniz Technical University, Engineering Faculty, Department of Geomatic Engineering, Trabzon, Turkey \\ (ertan@ktu.edu.tr)
}

ORCID ID 0000 - 0003 - 4284 - 5928; ORCID ID 0000 - 0002 - 3157 - 9188

*Corresponding Author, Received: 03/04/2018, Accepted: 16/04/2018

\begin{abstract}
The purpose of this study is to identify the deficiencies of the rangeland information system currently used in Turkey and, as an alternative, design a sustainable rangeland information system. In the study, both the extent of changes that occurred over time in the rangelands and the factors that caused such changes were identified, and solutions were suggested to eliminate those factors. The rangelands located in the Akçaabat district of Trabzon province were selected as the study area. Land use maps were produced by using the object-based classification method. According to the results of change analyses made with this information system, it was found out that, from 1973 to 2012, a surface area of 159.8 hectares had been degraded, demonstrating that the current information system had not been successful enough in the management of rangelands. For that reason, a sustainable rangeland information system free from all deficiencies was designed.
\end{abstract}

Keywords: Rangeland Information System, Worldview-2, Unmanned Aerial Vehicle, Support Vector Machine, Object Based Classification 


\section{INTRODUCTION}

Meadows and rangelands are perennial herbaceous plant communities that usually occur naturally in various particular lands (Altin et al., 2011). According to estimates, the rangeland ecosystem covers approximately $50 \%$ of the lands of the world (Wang et al., 2014) and meets $70 \%$ of the planet's needs for food for animals (Brown and Thorpe, 2008).

It is also widely accepted that, of all the lands in the world, rangelands have the most precious vegetation covers in terms of preventing global disasters such as erosion, vegetation fires, floods, and others (Avcioğlu, 2012). Furthermore, grasslands store at least $10 \%$ of global carbon stocks (Eswaran et al., 1993) and play an important role in the global carbon cycle (Scurlock and Hall, 1998). Grasslands are not only a significant food source for wild and domestic animals and a source of soil protection, but also have a major influence on the functioning of the terrestrial biosphere, the regional climate, and the ecological quality (Huang et al., 2012; Liu et al., 2014).

The total area of rangelands, which are thought to prevent global disasters as well as to provide countless other benefits, has decreased in Turkey from roughly 38 million hectares to about 14.6 million hectares in the last 60 years (Avcioğlu, 2012; Altın et al., 2011). If the extent of reduction in the total area of rangelands is taken into account, it is evident that rangelands have not been adequately controlled to ensure proper use and that improvements intended to remedy the degradation have not been fully implemented.

Unfortunately, in Turkey, the basic principles of rangeland management, such as determining the current grazing capacity and preparing and implementing rotational grazing plans, are generally not taken into consideration. As a result of such malpractice, rangelands today have lost much of their production potential (Ünal et al., 2012).

If images are not obtained, processed, and analyzed periodically, and if necessary interventions are not performed in a timely manner, an increasing number of deteriorations and losses in those areas is inevitable. The deterioration process affects all rangelands in the country of Turkey. Rangelands will inevitably become more like desert if the current situation continues.

Up to the present time, a great number of studies have been conducted by the use of both topographic measurements and satellite images for the purpose of determining the changes occurring in rangelands. For instance, Huang and et al., (2012) used Landsat MSS, TM/ETM images from the years 1954 to 2000 for graslands changes in the Northern Songnen Plain, China. After processing these images, analyzed the extent of change in the rangelands with the help of the information system they created. As a result of their study, they found that the total area of rangelands had diminished by $17.6 \%$ in those 46 years. On the other hand, Liu et al., (2011) examined the changes that had occurred in rangelands, forests, and agricultural lands in the years between 1982 and 2008 for the Loess Plateau, China. In their study, they performed analyses by using scanned topographic maps, infrared color aerial photographs, digital orthophotos, and SPOT-5 data integrated with the Geographic Information System
(GIS). In conclusion, they found that the number of parcel had increased, particularly between the years of 1982 and 1990, but, by force of rearranged land management policies, had decreased in the subsequent years. An et al., (2014) analyzed the change in rangelands from the years 1990 to 2004 by using NOAA/AVHRR-NDVI and MODIS-NDVI data, and a novel Local NPP Scaling (LNS) method for Qinghai, China. As a result of their study, they ascertained that the percentage of rangelands degradation had reached $36.7 \%$ during that 15 -year period.

Mansour et al., (2016), using SPOT-5 satellite images and an Random Forest (RF) classifier, produced thematic maps showing rangelands with an accuracy of $88.60 \%$. They claimed that the use of their thematic maps would be beneficial for developing policies for sustainable rangeland management.

With the development of unmanned aerial vehicles and the specifications of the cameras that have been used on such vehicles in recent years, those tools have begun to be commonly used for the monitoring of rangelands. For example, Rango et al., (2009) underlined that the Unmanned Aerial Vehicle (UAV) has yielded successful results in providing images and extraction of relevant features in the management and monitoring of rangelands. In their studies, Breckenridge and Dakins (2011) made bare ground determinations in the rangelands by using a helicopter UAV and a fixedwing UAV. As a consequence of that study, they stated that a helicopter UAV would be suitable for studies that require many details and high-precision photographs and that a fixed-wing UAV would be more suitable for studies in which large surfaces need to be covered. For four different studies, Laliberte et al., (2011) produced flora maps of the rangelands with $78-92 \%$ precision by using object-based classification that utilized the maps obtained from the Unmanned Aircraft Systems (UAS). Their studies showed that UAS were suitable platforms for producing flora maps of the rangelands in terms of providing very-high-resolution images. McGwire et al., (2013) defined green leaf cover in the rangelands with their NDVI (Normalized Difference Vegetation Index) by using images taken from unmanned aerial vehicles that used hyperspectral cameras. They compared the satellite image of a LANDSAT TM (Landsat Thematic Mapper) to NDVI results obtained from UAV images with land measurements. In the study, they stated that, because of the very high resolution of the hyperspectral images, it would be more suitable to use them in those kinds of studies.

It is possible to identify the reasons why rangelands degrade over time and eventually disappear. Those reasons may become evident through the analysis of databases created with the data obtained by using different measurement techniques, such as remote sensing, which is an effective tool for land use/cover mapping (Chen et al., 2015) and photogrammetry. Furthermore, with GIS and computer-aided systems, land evaluations can be performed more accurately, and more realistic land use/cover data, which is a fundamental input for environmental planning, management, and rangeland health, can be prepared (Burrough and McDonnell, 1998; Wu et al., 2016; Chen et al., 2015; Boswell et al., 2017). So, in local 
governments GIS are able to be used as a very strong device ( Iscan and Ilgaz, 2017).

Methodologically, remote sensing and photogrammetric techniques were used in the first section of this study, and the negative effects of problems encountered in rangelands were determined. In the next section, deficiencies in the current information system were identified. In the final section, a sustainable information system was designed to ensure efficient and proper management of the rangeland areas.

\subsection{Study area and Dataset}

The rangelands containing the borders of the Akçaabat district of the city of Trabzon were chosen as the field of study. Akçaabat, which is located on the northeastern coast of Turkey, is placed between $39^{\circ} 35^{\prime}$ East longitude and $41^{\circ} 01^{\prime}$ North latitude, at 10 meters altitude above sea level with a $353.66 \mathrm{~km}^{2}$ surface area. It is just to the west of the city of Trabzon (Figure 1).

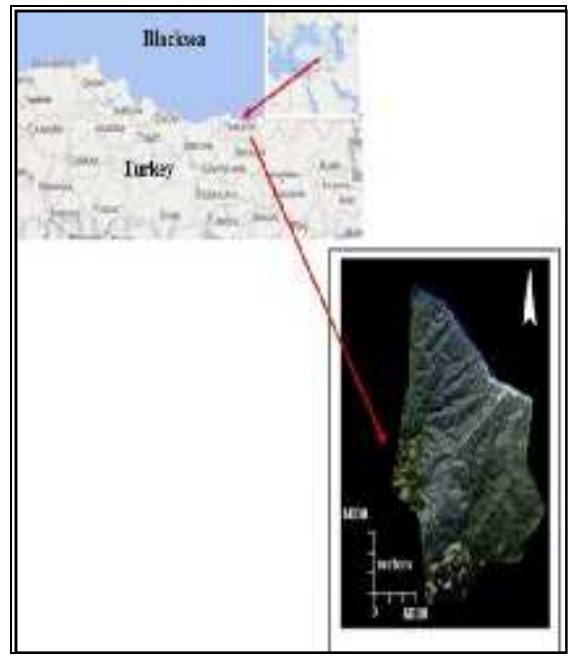

Figure 1. Study area

In the study area, to detect the changes occurring over time in the rangelands, aerial photos from the years 1973 and 1982, satellite images from the year 2012 and high resolution color photos obtained from a UAV were analysed. Aerial photos from 1973 with $58 \mathrm{~cm}$ spatial resolution and a scale of 1/23000 were composed of 71 pieces. Aerial photos from 1982 with the scale of $1 / 25000$ were composed of 45 pieces. A total of 116 pieces of stereoscopic aerial photos were used in the study.

Thirty-two Ground Control Points (GCPs) were used for the orthophoto process, and the coordinates of the GCPs were measured by means of the Continuously Operating Reference Station-Turkey (CORS-TR) Global Positioning System (GPS) technique. Then the interior and exterior orientation processes of the photos were completed with the Leica Photogrammetry Suite 9.0 software. Orthophoto images were generated by the use of oriented images.

After the orthophoto process, the orthophoto images were digitized by using the ArcMap software. The layers of rangeland, forests, roads, and buildings were established on the images. Rangeland areas were then calculated by extracting the building, forest, and road areas from the total area. After the digitization process, attribute information (rangeland names, years, types) of those layers was uploaded to the database, and a spatial database was created for all the rangelands.

Another form of data used was high-resolution WV2 MS (Multi Spectral) and PAN (Panchromatic) satellite images covering a $438 \mathrm{~km}^{2}$ area of the Akçaabat district, which were acquired in 2012 A WV-2 MS image has eight multispectral bands-Blue $(0.45-0.51 \mathrm{~m})$, Green $(0.51-0.58 \mathrm{~m})$, Red $(0.63-0.69 \mathrm{~m})$, Near Infrared 1 $(0.77-0.90 \mathrm{~m})$, Coastal $(0.40-0.45 \mathrm{~m})$, Yellow (0.59$0.63 \mathrm{~m})$, Red Edge $(0.71-0.75 \mathrm{~m}))$ and Near Infrared $2(0.86-1.04 \mathrm{~m})$-with 2-meter spatial resolution and the PAN band $(0.46-0.80 \mathrm{~m})$ with $50-\mathrm{cm}$ high spatial resolution.

The radiometric and atmospheric corrections of the satellite images were made by the company that supplies the images. The geometric correction of the satellite images consisted of 42 points, measured by the CORSTR (Continuously Operating Reference SystemTurkey) GPS method.

The Digital Terrain Model (DTM) widely used in all geosciences and engineering tasks (Y1lmaz and Uysal, 2017), was generated from a $1 / 25,000$-scaled Standard Topographic Map (STM) by using a rubber sheeting method. Finally, the images were rectified with the WV2 Rational Polynomial Coefficients (RPC) model, which contains an RPC of the WV-2 (MS) image in the ERDAS Imagine software (ERDAS Imagine, 2013), together with the produced DTM and GCPs. Overall, the Root Mean Square (RMS) errors were $1.31 \mathrm{~m}$ for the MS image and $0.39 \mathrm{~m}$ for the PAN image. RMS error is calculated with a distance equation (1)

$$
\text { RMS error }=\sqrt{\left(x_{r}-x_{i}\right)^{2}+\left(y_{r}-y_{i}\right)^{2}}
$$

wherex $x_{i}$ and $y_{i}$ define the coordinates of the input data and $\mathrm{x}_{\mathrm{r}}$ and $\mathrm{y}_{\mathrm{r}}$ define the retransformed coordinates.

The final data information was color aerial photos with $16-\mathrm{cm}$ spatial resolution that were taken by the Gatewing X100 UAV for the Balıklı, Hidırnebi, and Kuruçam rangelands, which are located in the district of Akçaabat, Trabzon. The study area consists of rangelands that are frequently used by the local community due to their closeness to the city centrum and to their popularity. Because of the vastness of the study area, it was divided into two sections. In the first section, 224, and in the second section, 144 photos were taken, making a total of 368 photos (Figure 2).
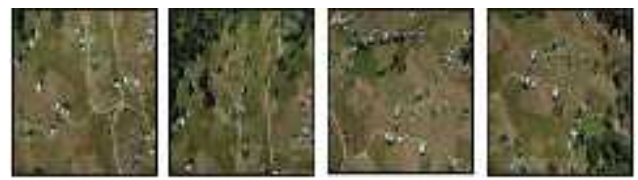

Figure 2. Color aerial photos with $16 \mathrm{~cm}$ spatial resolution that was taken by Gatewing X100 UAV

For the orthophoto processing of UAV images, 10 GCPs were established on the ground, and their positions were determined with the CORS-TR GPS technique. Aerial images were taken by the UAV, and then the photos were oriented by the Photoscan software. The RMS errors were found to be $0.11 \mathrm{~m}$ and $0.09 \mathrm{~m}$ for first and second sections, respectively. Then 
the DTM and ortho-image of the study area were generated.

\section{METHODOLOGY}

\subsection{Image Fusion}

The High-Pass Filter (HPF)technique, which was recommended by Schowengerdt (1980), was first used for reducing data volume and increasing the spatial resolution of Landsat MSS data (Carter, 1998). The HPF method is based on adding the high-frequency information from the high-resolution PAN image to each band of the low-resolution MS image to obtain the highresolution MS image (González-Audícana et al., 2004; Wang et al., 2005; Rokni et al., 2015). The first step of the HPF method is to calculate the ratio between the spatial resolutions of the input MS and PAN images. A high-pass kernel and its dimensions are determined according to that ratio. Once it is extracted, the highfrequency information from the panchromatic image, obtained by using the HPF, is added to each band of the multispectral image. It should be noted that the HPF image is weighted relative to the global standard deviation of the multispectral bands by using the weight factors calculated from the ratio. Finally, the new multispectral image is stretched to match the mean and standard deviation values of the original input multispectral inage (Klonus and Ehlers, 2009). HPF is described as follows:

$H P F_{i, j, k}=\left(M S_{i, j, k}+F P_{i, j}\right) / 2$

where MS is the multispectral image, HPF is the output image, $i$ and $i$ define the pixel location in the $k_{\text {th }}$ tand, and FP defines the high-pass filter (Han et al., 2008)

\subsection{Object Based Classification}

The principle of Object Based Image Analysis (OBIA) is to classify the image objects generated from the segmentation process (Kavzoğlu et al., 2015; Chen and Gao, 2014). OBIA includes several steps of image segmentation, training sample selection, and algorithm execution (Qian et al., 2015). First, the image is divided into image objects by a process of segmentation. Then, training samples for each class are collected from those image objects. The image objects are then classified with respect to a rule-based procedure or by using machine learning based on training samples, such as the $\mathrm{K}$ nearest-neighbor classifier, in which fuzzy membership functions are used to assign objects to the classes in the Cognition software (eCognition, 2012), decision tree, and Support Vector Machine (SVM) (Qian et al., 2015).

Image segmentation, which is first step of OBIA, is dividing an image into different types of regions or classes and recognizing the objects (Farnoosh and Zarpak, 2008). In other words, segmentation is the grouping of pixels to form meaningful objects with respect to spatial and spectral information ( $\mathrm{Li}$ et al., 2011). Multi-resolution segmentation, which was developed by Baatz and Schäpe (2000) and has different homogeneity criteria for image objects based on spectral and/or spatial information, is the most widespread segmentation method in eCognition software
(eCognition, 2012), The first step of this segmentation process is each pixel forming one image object or region. A pair of image objects is merged into one larger object at each step. The principle of the merging decision is the local homogeneity criterion, describing the similarity of adjacent image objects (Baatz and Schäpe, 2000). The criterion stops when heterogeneity among the objects is at a maximum and homogeneity among the objects is at a minimum (Li et al., 2011).

The homogeneousness criterion used in segmentation is defined by Equation 3:

$\mathrm{h}=\mathrm{w}_{\text {color }} \cdot \mathrm{h}_{\text {color }}+\left(1-\mathrm{w}_{\text {color }}\right) \cdot \mathrm{h}_{\text {shape }}$

where fusion factor (h) contains object features, such as shape and color, $w_{\text {color }}$ defines the weight of each

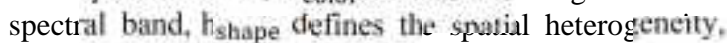
and $h_{c o l o r}$ defires the spectral ficterogeneily.

$\mathrm{h}_{\text {color }}=\sum_{c} \mathrm{w}_{\mathrm{f}}\left(\mathrm{n}_{03} \cdot \sigma_{\mathrm{c}}^{03}-\left(\mathrm{n}_{\mathrm{ol}} \cdot \sigma_{\mathrm{c}}^{\mathrm{ol}}+\mathrm{n}_{02} \cdot \sigma_{\mathrm{c}}^{02}\right)\right)$

where $\mathrm{w}_{\mathrm{c}}$ defines the weight of $\mathrm{c}$ spectral band, $\mathrm{n}_{\mathrm{o3}}$ defines the number of pixels in the object to be merged, $\mathrm{n}_{\mathrm{o} 1}$ defines the number of pixels in Object $\mathrm{l}, \mathrm{n}_{\mathrm{oz}}$ defines the number of pixels in Object $2, \sigma_{c}^{03}$ defines the variance of the objects to be merged, $\sigma_{\mathrm{c}}^{\mathrm{ol}}$ defines the variance of Object 1 , and $\sigma_{c}^{o 2}$ defines the variance of Object 2 in Equation 4.

The shape of heterogeneity ( $h_{\text {shape}}$ ) is calculated by compactness ( $\left.\mathrm{h}_{\text {comp }}\right)$ and smoothness ( $\left.\mathrm{h}_{\text {smooth }}\right)$ components (Equation 5).

$\mathrm{h}_{\text {shape }}=\mathrm{w}_{\text {comp }} \cdot \mathrm{h}_{\text {comp }}+\left(1-\mathrm{w}_{\text {comp }}\right) \cdot \mathrm{h}_{\text {smooth }}$

The combination process stops when the $\mathrm{f}$ (scale parameter) reaches a pre-calculated threshold value. While a smaller-scale parameter yields smaller object sizes, a larger-scale parameter results in larger object sizes. The scale parameter is used to control the average image object size (Baatz and Schäpe, 2000).

\subsection{Support Vector Machines}

SVM classification based on statistical learning theory is a controlled classification algorithm (Karakus et al., 2017). The non-linear mapping of input data in a very high-dimensional space is the basis for Support Vector Machines (SVM) in both. Given a training data set of two separable classes, with samples represented by $\left(\mathrm{x}_{1}, \mathrm{y}_{1}\right) \ldots\left(\mathrm{x}_{\mathrm{r}}, \mathrm{y}_{\mathrm{r}}\right)$, where $\mathrm{x} \in \mathrm{R}^{\mathrm{N}}$ is an $\mathrm{N}$-dimensional space, and $y \in\{+1,-1\}$ is the class label, a hyperplane separates two classes according to equation 6 :

$w x_{i}+b \leq-1$ for $y_{i}=-1$, and $w x_{i}+b \geq 1$ for $y_{i}=1$

where, $\mathbf{w}$ is the weight vector $\left(\mathbf{w}=\left\{\mathbf{w}_{1}, \mathbf{w}_{2} \ldots \mathbf{w}_{\mathbf{n}}\right\}\right)$. $\mathbf{n}$ defines the number of attributes, and $\mathbf{b}$ defines a constant.

The distance between two hyperplanes is determined by $\frac{2}{\|w\|}$, The optimum hyperplane, which separates two classes, can be determined by minimizing $\|\mathrm{w}\|^{2}$. In case two classes are not linearly separable, $\varepsilon_{\mathrm{f}}$ slack variable is used to find the hyperplane with the maximum distance. (Equation 7): 
$y_{i}\left(w x_{i}+b\right)-1+\varepsilon_{i} \geq 0$

To make the classification error minimum and the distance between two hyperplanes maximum, a userdefined positive turning parameter, $\mathrm{C}$, is used (Equation 8) (Song et al., 2012):

$\min \left\{\frac{1}{2}\|\mathrm{w}\|^{2}+\mathrm{C} \sum_{\mathrm{i}=1}^{\mathrm{n}} \varepsilon_{\mathrm{i}}\right.$

Another parameter used is a kernel function, which is applied when the data are not separated linearly. These functions tiansform data to a higher-dimensional space where two classes are separated. The decision rule is obtained and defined as Equation 9. In this equation, $\boldsymbol{\alpha}_{i}, \mathbf{i}=\mathbf{1}$.. $\mathbf{r}$ are Lagrange multipliers, and $\mathbf{K}\left(\mathbf{x}_{i}, \mathbf{x}_{\mathbf{i}}\right)$ is a kernel function (Tso and Mather, 2009):

$f(x)=\operatorname{sign}\left(\sum_{i=1}^{n} \alpha_{i} y_{i} K\left(x_{i}, x_{i}\right)+b\right)$

There are many well-known kernels, such as Polynomial, Radial, Gaussian and Sigmoid functions. Kavzoğlu and Çölkesen (2010) pointed out that the Radiul-based kernel yields the best results of those kernels. A Radial-based kernel is defined as:

$\mathrm{K}\left(\mathrm{x}_{i}, \mathrm{x}_{\mathrm{i}}, \sigma\right)=\exp \left(-\gamma\left\|\mathrm{x}_{\mathrm{i}}-\mathrm{x}_{\mathrm{i}}\right\|^{2}\right), \gamma>$

\subsection{Classification Process}

There were many different land use classes, for example, building 1, concrete (white)-roofed building; building 2, tile (red)-roofed building; and building 3, sheet metal (black)-roofed building in the study area. The WorldView-2 satellite image used in the study was fused to better distinguish such land use classes. The HPF fusion method was preferred to preserve the spectral characteristics of images better and to produce better results (Gül et al., 2013; Nikolakopolos et al., 2015).

Segmentation and classification procedures are the two main steps of the object-based approach. First, the image is divided into sub-segments by segmentation. Each sub-segment is called an image object. Then, sample areas for each class are collected from these segments. The segments are then classified with respect to the collected segments.

In this study, optimal parameter values for segmentation, for example, scale parameter, shape, and compactness, were first defined by user trial-and-error. Optimal parameter values of scale parameter, shape, and compactness were $100,0.5$ and 0.1 , respectively. Then, images were divided into segments according to the optimal parameters. Finally, those segments were classified by using the SVM algorithm in the eCognition software (Figure 3).

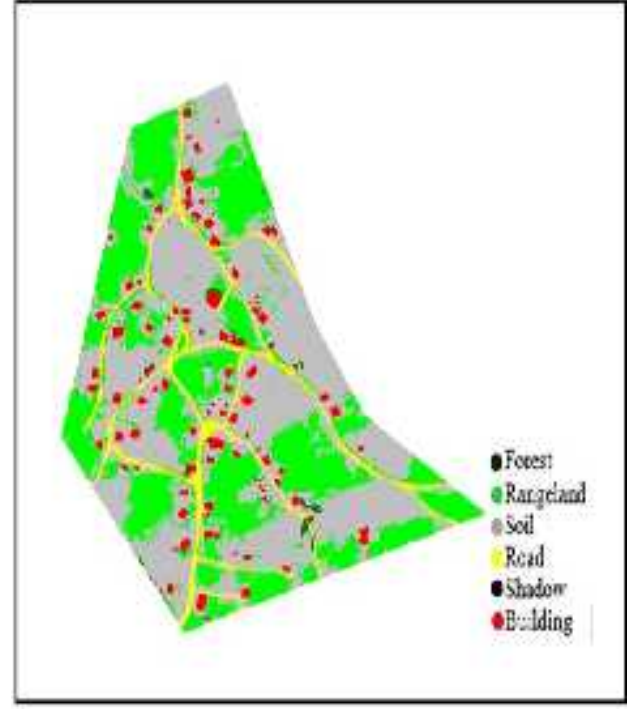

Figure 3. Classified image

To improve the classification accuracy, the classes that were mixed as a consequence of segmentation were separated from each other through rule sets. In those rule sets, the NDVI and ZABUD indexes were used to increase the segmentation accuracy as well as spectral information. NDVI values of the MS images of the study area were calculated by utilizing the formula below:

$N D V I=\frac{N I R-R e d}{N I R+R e d}$

The green field and soil classifications, especially, were separated from each other through the use of the NDVI. In addition to this, for the separation of building and road classification, the ZABUD index, found in Lewinski (2006) was utilized. The ZABUD index used for the $W V-2$ satellite image was calculated by the equation of:

$$
\begin{aligned}
& \text { ZABUD }=\left[(\text { Green }- \text { Red })^{2}+(\text { Red }- \text { Red_edge })^{2}+\right. \\
& (\text { Red_edge }- \text { NIR1 })^{2}+(\text { NIR1 }- \text { NIR2 })^{2}+ \\
& \left.(\text { NIR2 }-P A N)^{2}\right]^{0.5}
\end{aligned}
$$

Finally, shadow classes are included in those classes by combining them with the neighboring classes. Thematic images were obtained to produce land use maps. Those images were then added to the database after being converted to vector data. Change detection analyses were fulfilled through the queries of the database.

\subsection{Accuracy Assessment}

The multinomial distribution approach suggested by Congalton and Green (1999) was utilized for accuracy assessment. The confidence interval was selected as $95 \%$, and the degree of freedom as 1 . Class numbers in the study area were defined as 4 in the Ağaçlı and Limanoba rangelands, 6 in Karadağ and Simba rangelands, and 5 in other rangelands. Also, to determine a one-year change in the rangelands enjoying high popularity, class 9 was chosen in the accuracy assessment in the study undertaken. To use them in the 
accuracy assessment, numbers for each of the classes were randomly omitted in compliance with the "stratified random" method; namely, points were omitted in regard to the space that they occupied on maps. To create the error matrix in the multinomial distribution approach, omitting 30 points is sufficient on behalf of each class (Congalton, 2001). Thus, a minimum of 30 points was chosen for the analyses.

For the minimum number of points to be used in the accurily analysis, equation 13 was used.

$\mathrm{n}=\frac{\mathrm{B}}{4 \mathrm{~b}^{2}}$

In equation $13, \mathbf{B}$ is the equivalent of the value calculated with $\frac{\alpha}{k}$ at a degree of freedom of 1 in the distribution table of $\chi^{2}$ according to $\boldsymbol{k}$ number of classes and $\boldsymbol{\alpha}$ margin of error. Here, $\boldsymbol{b}$, stands for the margin of error, and $\boldsymbol{n}$ stands for the min mum number of samples. An error matrix is frequently used to assess the thematic accuracy of a land cover map (Stehman, 1997). For that purpose, error matrices were created to assess the accuracy of each classification result, using a minimum point number calculated with equation 13 according to class numbers (Table 1).

Table 1. Minimum points for accuracy assessment

\begin{tabular}{|c|c|c|c|}
\hline $\begin{array}{c}\text { Class } \\
\text { Number }\end{array}$ & $\alpha / \mathrm{k}$ & $\chi^{2}$ & $\begin{array}{c}\text { Minimum point } \\
\text { number }\end{array}$ \\
\hline 5 & 0.010 & 6.64 & 664 \\
\hline 6 & 0.008 & 7.05 & 705 \\
\hline 9 & 0.005 & 7.74 & 774 \\
\hline
\end{tabular}

Overall, classification accuracies obtained with error matrices and kappa values calculated are given in Figure 4.

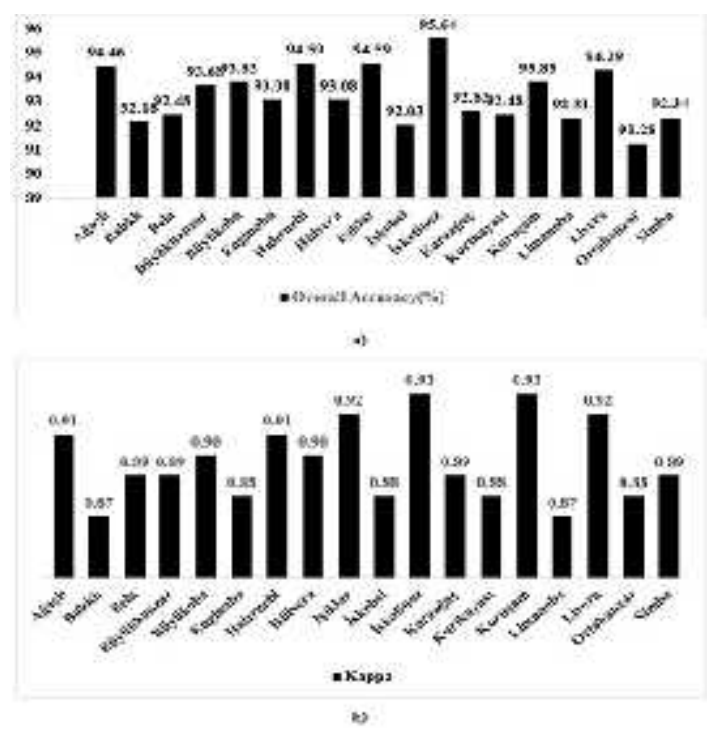

Figure 4. a) Overall classification accuracies b) Kappa values
Kappa values were calculated by using equation 14 (Keno et al., 2014).According to Figure 4, overall classification accuracies of between $91.28 \%$ and $95.64 \%$ were obtained for 19 rangelands.

Kappa $=\frac{\text { (observed accuracy-chance agreement })}{(1 \text {-chance agreement })}$

\section{Result and Discussion}

\subsection{Change Detection}

In the study, up-to-date and past land use maps were generated for change detection analysis of the rangelands. According to the change detection analysis, the building areas, which had been defined as 6 hectares, reached 6.9 hectares by increasing $15 \%$ by the year 1982, while the number of the buildings increased from 1085 to 1190 . Road areas increased from 22.8 hectares to 30.6 hectares, the road length reached 83 kilometers, with an increase of $22 \%$ from 15 kilometers. Forestlands regressed to 74.5 hectares with a decrease of 0.9 hectare. As a consequence, it was determined that rangelands regressed to 1184.9 hectares, with a decrease of 7.8 hectares (Table 2).

Table 2. The total amount changes of all the rangelands over the years.

\begin{tabular}{|c|c|c|c|c|c|c|c|}
\hline \multirow{2}{*}{ Year } & \multicolumn{2}{|c|}{ Building } & \multicolumn{2}{|c|}{ Road } & $\begin{array}{c}\text { Rangeland } \\
+ \\
\text { Soil }\end{array}$ & $\begin{array}{c}\text { Fores } \\
\mathrm{t}\end{array}$ & Lake \\
\cline { 2 - 8 } & $\begin{array}{c}\text { Area } \\
\text { (ha) }\end{array}$ & Number & $\begin{array}{c}\text { Area } \\
\text { (ha) }\end{array}$ & $\begin{array}{c}\text { Length } \\
\text { (km) }\end{array}$ & $\begin{array}{c}\text { Area } \\
\text { (ha) }\end{array}$ & $\begin{array}{c}\text { Area } \\
\text { (ha) }\end{array}$ & $\begin{array}{c}\text { Area } \\
\text { (ha) }\end{array}$ \\
\hline 1973 & 6 & 1085 & 22.8 & 68 & 1192.7 & 75.4 & 0 \\
\hline 1982 & 6.9 & 1190 & 30.6 & 83 & 1184.9 & 74.5 & 0 \\
\hline 2012 & 17.5 & 2156 & 60 & 138 & 10329 & 186.6 & 0.9 \\
\hline
\end{tabular}

According to the analysis of the extent of change between the years of 1982 and 2012, the building areas increased from 6.9 hectares to 17.5 hectares, with a $154 \%$ increase. In addition, the number of buildings increased from 1190 to 2156, with an $81 \%$ increase. According to the analysis of the extent of change between the years of 1973 and 2012, road area and length also increased in proportion to the number of buildings. Road areas increased from 30.6 hectares to 60 hectares, while the road length value increased from 83 $\mathrm{km}$ to $138 \mathrm{~km}$. Similarly, the forestlands in rangelands in which there was no placement increased from 74.5 hectares to 186.6 hectares. Reforestation in the rangelands contributed to that increase. When those areas (building, road, forest, and lake areas) were subtracted from the total areas, rangeland areas regressed from 1184.9 hectares to 1032.9 hectares (Table 2).

Furthermore, the annual changes between the years 2012 and 2013 were examined for the Hidırnebi, Kuruçam, and Balıklı rangelands, which are close to the city center and commonly used. According to the annual change in those rangelands, the number of buildings reached 447, with an increase of 39 buildings. The total of the building areas was 3.89 hectares, with an increase of 0.28 hectares. Also, when the road area increased by 0.64 hectare, the road length increased by 2 kilometers. The soil area decreased by 0.26 hectares, and the forest 
land decreased by 1.04 hectares. A large portion of the decreased soil area was made up of areas that were converted into fields, planted in 2012, and then nonplanted in 2013. Consequently, the total extent of decrease in those three rangelands was determined to be 2.86 hectares (Table 3 ).

Table 3. The one year change in the pilot stud

\begin{tabular}{|c|c|c|c|c|c|c|c|}
\hline \multirow{2}{*}{ Year } & \multicolumn{2}{|c|}{ Building } & Road & Rang. & Soil & Field & Forest \\
\cline { 2 - 7 } & $\begin{array}{c}\text { Area } \\
\text { (ha) }\end{array}$ & Number & $\begin{array}{c}\text { Area } \\
\text { (ha) }\end{array}$ & $\begin{array}{c}\text { Area } \\
\text { (ha) }\end{array}$ & $\begin{array}{c}\text { Area } \\
\text { (ha) }\end{array}$ & $\begin{array}{c}\text { Area } \\
\text { (ha) }\end{array}$ & $\begin{array}{c}\text { Area } \\
\text { (ha) }\end{array}$ \\
\hline 2012 & 3.61 & 408 & 6.5 & 95.41 & 3.13 & 21.69 & 8.37 \\
\hline 2013 & 3.89 & 447 & 7.14 & 92.55 & 2.87 & 24.93 & 7.33 \\
\hline
\end{tabular}

As seen above, the decrease in rangelands continues each passing day. In the process seen from last year, the rapid increase in the number of the buildings demonstrates this. The destruction will be parallel with the increased number of buildings, and destruction of the rangeland areas will increase.

\subsection{Current Rangeland Information System}

The existing rangeland information system has been built in an attempt to ensure centralized management of rangelands by preventing data confusion and protecting rangelands. The current information system contains information about not only the surface areas and borders of rangelands, but also the properties of rangelands (inclination, land use class, and number of livestock). The majority of the data about the condition of lands recorded in the current system is obtained through field studies. Studies conducted on areas having very large surface areas cannot be frequently conducted or updated. As a consequence, changes in the areas cannot be detected in a timely manner.
If the data infrastructure of the current rangeland information system shown in Figure 5 is reviewed, it is evident that the system is used for archiving the information entered and for querying the existing information rather than for identifying problems related to rangelands, suggesting solutions, or performing processes and analyses to that end.

If the extent of change ascertained within the scope of the study is analyzed, it is understood that those areas have not been used properly and that controls have not been carried out to their full extent. Persistence of these problems can be explained by mismanagement and incapability.

\subsection{Designing A Sustainable Rangeland Information System}

Given the change analysis results, it is thought that the destruction of rangelands persists to the present day, and, if necessary measures are not taken, will continue to a greater degree.

Thus, deficiencies of the information system currently used in the management of rangelands were identified, and a sustainable rangeland information system directed to solve these problems was suggested. The system designed in Figure 6 is based on the images of rangelands, which are obtained by remote sensing and photogrammetric techniques, and on thematic maps, which are produced from these data by image processing techniques. Furthermore, vector and raster data that need to be used or produced for different analyses, which can be conducted in the information system and attribute information, are demonstrated in the model.

A major part of the data that can be used in analysis and evaluation studies was produced in the information system designed within the framework of the study. For example, previous and current land use maps, forming the basis of the model, and maps of change, formed for the purpose of determining the change in land use, were produced. Also, a digital terrain model was produced by using high-resolution aerial photographs.

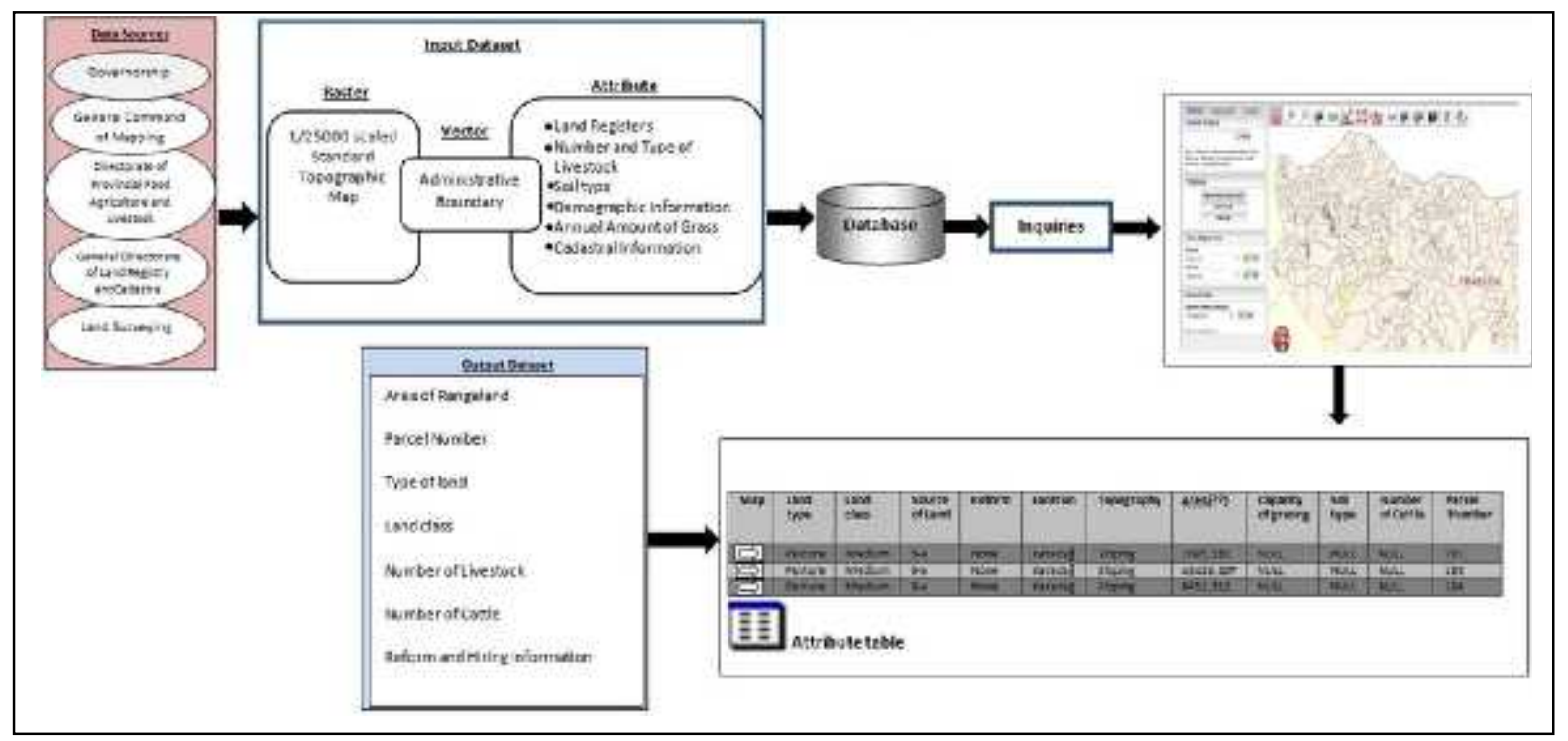

Figure 5. Current rangeland information system 


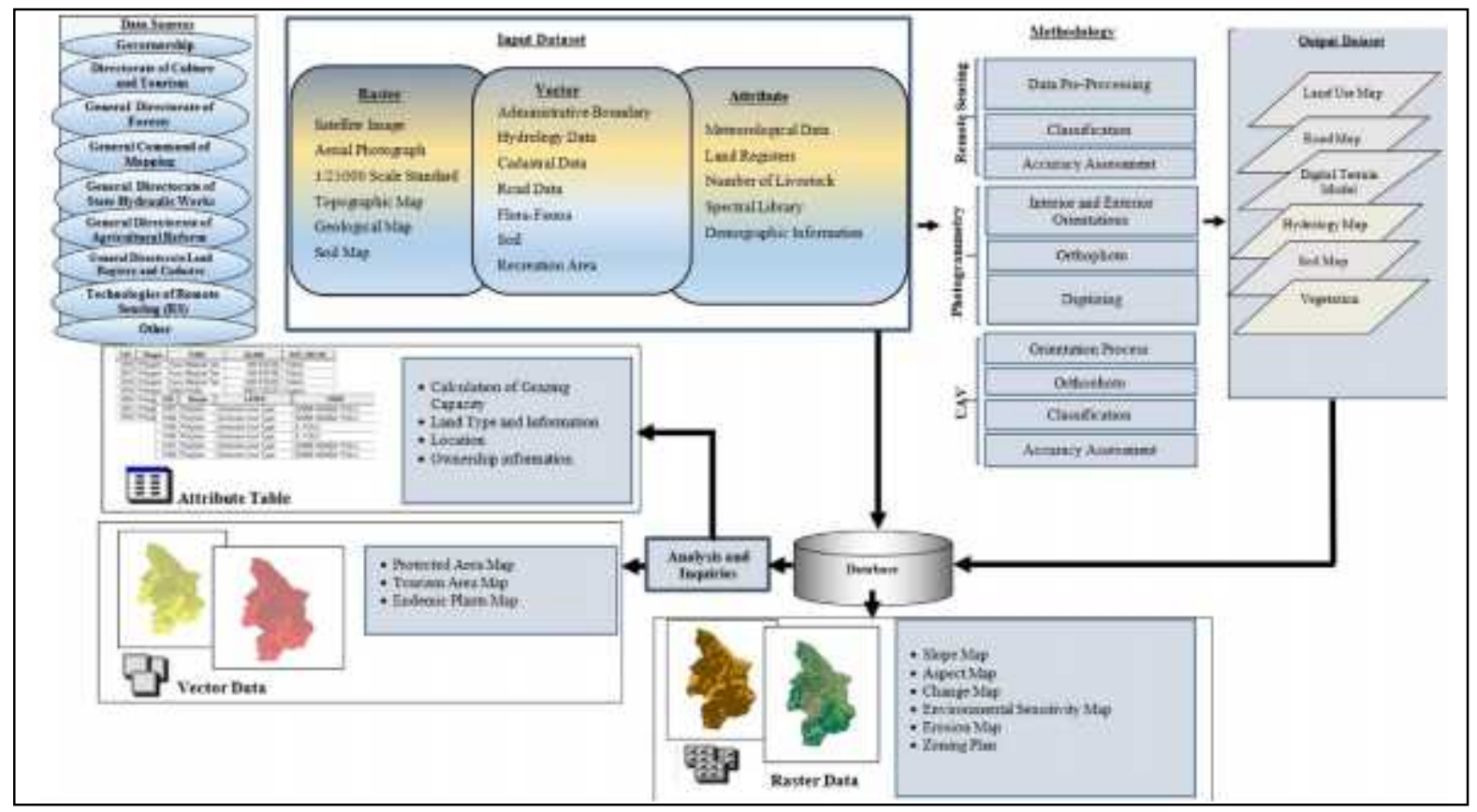

Figure 6. A new rangeland information system

Furthermore, a present-time map was generated by using UAV images, and up-to-date road network maps were generated by using WV-2 images (Figures 7 and $8)$.

The most important feature of the information system designed is that it is sustainable, because data is obtained periodically, and it has a dynamic structure. It allows for making all kinds of analyses and evaluations. When maps are produced following classification of the images obtained periodically, any change that occurs in the land will be detected, and problems will be responded to in a timely manner.

For instance, with these maps it will be possible to detect shanty settlements in rangelands, as well as accompanying problems, deterioration in land structure, and conditions of the rangelands in a short time. As rangelands are periodically monitored, diseases and deteriorations in rangelands will be identified, and the thematic maps produced will greatly contribute to the determination of the areas that need to be prioritized in the intended improvement projects.

It will also be possible to make analyses and evaluations in digital environments for many different study areas by using the data generated from the information system. Result maps may also be produced, including those of studies intended to determine the most suitable locations for areas to be offered to tourism. The information system may also produce environmental protection maps, erosion maps, current road maps and road network plans for new roads to be built, grazing plan maps (to be generated by using aspect maps), endemic species maps, and maps for determining plant species protection areas.

In addition to those, further studies that are of great importance for rangelands and must be included in the information system need to be conducted. One of the most significant studies to be conducted is the recalculation of rangeland grazing capacities by the use of remote sensing techniques and data about current land conditions to generate maps showing the rangelands' grass diversity. Those studies must utilize satellite images taken periodically or hyperband images taken by a UAV, as well as data obtained as a result of field studies performed simultaneously with the imaging.

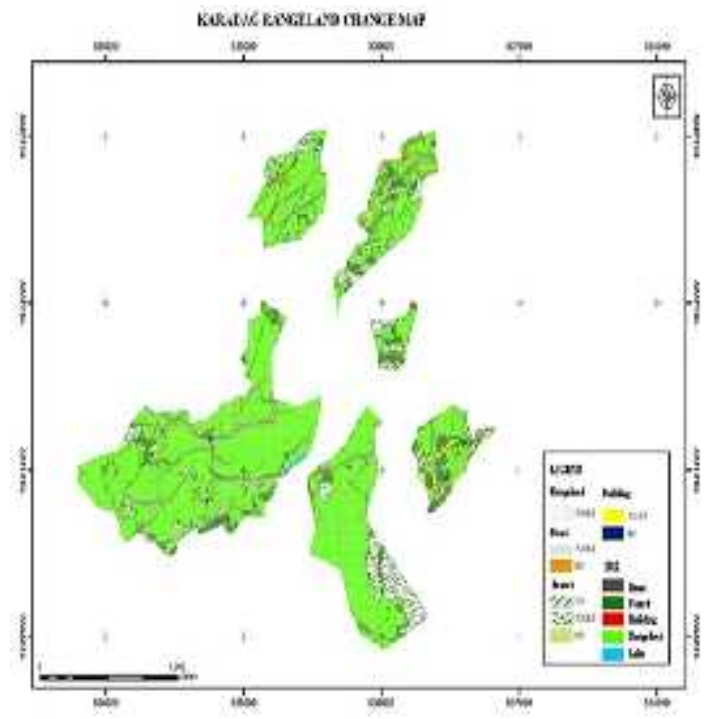

Figure7. Karadag rangeland change map

Ultimately, with this designed information system, a single institution will again have power and responsibility. In addition, the ability to obtain a major part of the data quickly and periodically by means of remote sensing technologies will introduce to the information system the capabilities of query, sustainability, and analysis and evaluation, along with principles of objectivity. With such a rangeland management system, rangelands will be protected, and the national economy will improve by increasing rangeland productivity. 


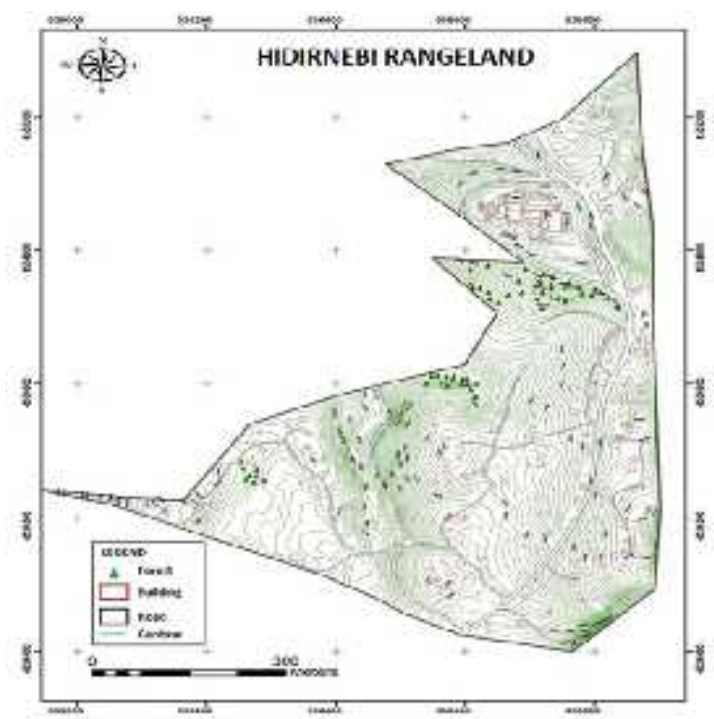

Figure 8. Hidırnebi present time map

\section{CONCLUSION}

In the scope of this study, land use maps of rangelands were generated for past and current years. Then, by using these maps, temporal changes in rangelands were determined. A database was created with information about the rangelands in the study area for analyses and queries. According to the results of the study, the structure of the current rangeland information system was examined, deficiencies were identified, and a sustainable rangeland information system was designed with the aim of eliminating the deficiencies.

The results of the study demonstrate that, in the event necessary inspections and controls are not carried out in rangelands, negative effects will occur in increasing proportions. To protect and maintain those areas, it is very important to periodically monitor the areas, to promptly respond to the problems identified, and to recover any damage that occurs - all of which are possible only through sustainable rangeland management.

\section{References}

Altin, M., Gökkuş, A., Koç, A., 2011. Çayırvemerayönetimi [Grassland and rangeland management], 1st ed, OnurGrafik, Ankara, pp 376.

An, R., Wang, Z., Wang, H. L., Wu, H., Quaye-Ballard, J.A., 2014. Monitoring rangeland degradation on the "Three River Headwaters" region in 1990 and 2004, Qinghai, China, Proceedings of the 35th IEEE International Geoscience and Remote Sensing Symposium, July 13-18 Quebec-Canada, IEEE, 3526 3529.

Avcioğlu, R., 2012. Turkish grasslands and acquisitions by pasture law, Research Journal of Agricultural Sciences, 1, 24-32.

Baatz, M. and Schäpe, A., 2000. Multiresolution segmentation an optimization approach for high quality multi scale image segmentation, J. Strobl, T. Blaschke, G. Griesebner (Eds.), Angewandte Geographische
Informations Verarbeitung XII, Wichmann Verlag, Heidelberg, pp. 12-23.

Boswell, A., Petersen, S., Roundy, B., Jensen, R., Summers, D., Hulet, A., 2017. Rangeland monitoring using remote sensing: comparison of cover estimates from field measurements and image analysis, AIMS Environmental Science, 4 (1), 1-16.

Breckenridge, R.P. and Dakins, M.E., 2011. Evaluation of bare ground on rangelands using unmanned aerial vehicles: a case study, GIScience and Remote Sensing, 48 (1), 74-85.

Brown, J.R. and Thorpe, J., 2008. Climate change and rangelands: responding rationally to uncertainty, Rangelands, 30 (3), 3-6.

Burrough, P.A. and Mcdonnell, R.A., 1998. Principles of Geographical Information Systems, Oxford University Press, New York, 34 p.

Carter, D.B., 1998. Analysis of Multiresolution Data Fusion Techniques, M.Sc Thesis, Blacksburg, Virginia: Virginia Polytechnic Institute and State University, 54 p.

Chen, J., Chen, J., Liao, A., Cao, X., Chen, L., Chen, X., He, C., Han, G., Peng, S., Lu, M., Zhang, W., Tong, X., Mills, J., 2015. Global land cover mapping at $30 \mathrm{~m}$ resolution: a POK-based operational approach. ISPRS Journal of Photogrammetry and Remote Sensing, 103, 727.

Chen, Z.Y. and Gao, B.B., 2014. An object based method for urban land cover classification using airborne lidar data, IEEE Journal of Selected Topics in Applied Earth Observations and Remote Sensing, 7(10), 4243-4254.

Congalton, R.G. and Green, K., 1999. Assessing the accuracy of remotely sensed data: principles and practices, Lewis Publishers, Boca Raton, 137 p.

Congalton, R.G., 2001. Accuracy assessment and validation of remotely sensed and other spatial information, International Journal of Wild land Fire, 10(4), 321-328.

Cortes, C. And Vapnik, V., 1995. Support vector networks, Machine Learning, 20(3), 273-297.

eCognition. eCognition Developer 8.7.2 User Guide, Definiens AG, Germany.

ERDAS Imagine, 2013. ERDAS Imagine 2013 User Guide, 2801 Buford Highway, N.E. Atlanta, Georgia, USA.

Eswaran, H., Van Den Berg, E., Reich, P., 1993. Organic carbon in soils of the world, Soil Science Society of America Journal, 57, 192-194.

Farnoosh, R. And Zarpak, B., 2008. Image segmentation using Gaussian Mixture Model, International Journal of Engineering Science (IUST), 19(1-2), 29-32. 
Gonzalez-Audicana, M., Saleta, J.L., Catalan, R.G., Garcia, R., 2004. Fusion of multispectral and panchromatic images using improved IHS and PCA mergers based on wavelet decomposition, IEEE Transactions on Geoscience and Remote Sensing, 42(6), 1291-1299.

Gül, B., Yıldırmış, Ç.,Değer, A., Erdoğan, M., Ulubay, A.2013. Görüntübirleştirmeyöntemlerinin spectral değerlerivegörüntükalitesinikorumaaçısındankarşılaştırıl mas1: Worldview-2 uygulaması [A comparison of image fusion methods in terms of spectral values of images and protection of image quality: Worldview-2 application], Harita Dergisi, 150, 8-17.

Han, S.S., Li, H.T., Gu, H.Y., 2008. The Study on Image Fusion for High Spatial Resolution Remote Sensing Images. The International Archives of the Photogrammetry, Remote Sensing and Spatial Information Sciences. Vol. XXXVII. Part B7 Beijing, 1159-1164.

Huang, F., Wang, P., Zhang, J.J. 2012. Grasslands changes in the Northern Songnen Plain China during 1954-2000, Environmental Monitoring and Assessment, $184,2161-2175$.

Iscan, F. and Ilgaz, A, 2017. Analysis Of Geographic/Urban Information System Web Presentations Of Local Goverments In Turkey, International Journal of Engineering and Geosciences (IJEG), Vol; 2; Issue; 03, pp. 75-83.

Karakus, P., Karabork, H., Kaya, S., 2017. A Comparison Of The Classification Accuracies In Determining The Land Cover Of Kadirli Region Of Turkey By Using The Pixel Based And Object Based Classification Algorithms, International Journal of Engineering and Geosciences (IJEG), Vol; 2; , Issue; 02, pp. 52-60.

Kavzoğlu, T. and Çölkesen, I., 2010. Destekvektörmakineleriileuydugörüntülerininsınıflandırı lmasında kernel fonksiyonlarınınetkilerininincelenmesi [Investigation of the effects of kernel functions in satellite image classification using support vector machines], HaritaDergisi, 144, 73-82.

Kavzoglu, T., Çölkesen, I., Yomralioğlu, T., 2015. Object-based classification with rotation forest ensemble learning algorithm using very high resolution WorldView-2 image, Remote Sensing Letters, 6(11), 834-843.

Keno, B., Suryabhagavan, K.V.2014. Multitemporal remote sensing of landscape dynamics and pattern change in Dire district, southern Ethiopia, Journal of Geomatics, 8 (2).

Klonus, S. and Ehlers, M., 2009. Performance of evaluation methods in image fusion, 12th International Conference on Information Fusion, International Society of Information fusion, Seattle, 6-9 July, Washington.
Laliberte, A.S., Winters, C., Rango, A., 2011. UAS remote sensing missions for rangeland applications, Geocarto International, 26, 141-156.

Lewinski, S., 2006. Applying fused multispectral and panchromatic data of Landsat ETM+ to object oriented classification, 26th EARSeL Symposium, New Developments and Challenges in Remote Sensing, May 29-June 2, Warsaw, Poland.

Li, S., Xie, Y., Meng, L., 2011. Monitoring land cover changes in HulunBuir by using object oriented method, Proceedings of the Multitemporal Conference, IEEE, pp. 29-32.

Liu, D., Li, B., Liu, X., Warrington, D.N., 2011. Monitoring land use change at a small watershed scale on the Loess Plateau, China: applications of landscape metrics, remote sensing and GIS, Environmental Earth Sciences, 64, 2229-2239.

Liu, X.Y., Liang, T.G., Guo, Z.G., Long, R.G., 2014. A rangeland management pattern based on functional classification in the Northern Tibetan Region of China, Land Degradation and Development, 25(2), 193-201.

Mansour, K., Mutanga, O., Adam, E., Abdel-Rahman, E.M., 2016. Multispectral remote sensing for mapping grassland degradation using the key indicators of grass species and edaphic factors, Geocarto International, 31(5), 477-491.

Mcgwire, K.C., Weltz, M.J., Finzel, A., Morris, C.E., Fenstermaker, L.F., Mcgraw, D.S., 2013. Multiscale assessment of green leaf cover in a semi-arid rangeland with a small unmanned aerial vehicle, International Journal of Remote Sensing, 34(5), 1615- 1632.

Nikolakopolos, K. And Oikonomidis, D., 2015. Quality assessment of ten fusion techniques applied on Worldview-2, European Journal of Remote Sensing, 48, 141-167.

Qian, Y., Zhou, W., Yan, J., Li, W., Han, L., 2015. Comparing machine learning classifiers for object based land cover classification using very high resolution imagery, Remote Sensing, 7, 153-168.

Rango, A., Laliberte, A., Herrick, J.E., Winters, C., Havstad, K., Steele, C., Browning, D., 2009. Unmanned aerial vehicle-based remote sensing for rangeland assessment, monitoring, and management, Journal of Applied Remote Sensing, 3, 1-15.

Rokni, K., Ahmad, A., Solaimani, K., Hazini, S., 2015. A New approach for surface water change detection: integration of pixel level image fusion and image classification techniques, International Journal of Applied Earth Observation and Geoinformation, 34, 226-234.

Schowengerdt, R.A., 1980. Reconstruction of multispatial, multispectral image data using spatial frequency content, Photogrammetric Engineering and Remote Sensing, 46(10), 1325-1334. 
Scurlock, J.M.O. and Hall, D.O., 1998. The global carbon sink: a grassland perspective, Global Change Biology, 4(2), 229-233.

Stehman, S.V., 1997. Selecting and interpreting measures of thematic classification accuracy, Remote Sensing of Environment, 62(1), 77 - 89.

Song, X.F., Duan, Z., Jiang, X.G., 2012. Comparison of artificial neural networks and support vector machine classifiers for land cover classification in Northern China using a SPOT-5 HRG image, International Journal of Remote Sensing, 33, 3301-3320.

Tso, B. And Mather, P.M., 2009.Classification methods for remotely sensed data, Second Edition, Taylor \& Francis Group, United States of America, 376 p.

Ünal, S., Mutlu, Z., Mermer, A., Urla, Ö.,Ünal, E., Özaydın, K.A., Avă̆, A., Yıldız, H., Aydoğmuş, O., Şahin, B., Arslan, S., 2012. A Study on Determination of Condition and Health of Rangelands in Çankırı Province, Research Journal of Agricultural Sciences, 5(2), 131-135.
Wang, J., Brown, D.G., Bai, Y., 2014. Investigating the spectral and ecological characteristics of grassland communities across an ecological gradient of the Inner Mongolian grasslands with in situ hyperspectral data, International Journal of Remote Sensing, 35(20), 71797198.

Wang, Z., Ziou, D., Armenakis, C., Li, D., Li, Q., 2005. A comparative analysis of image fusion methods, IEEE Transactions on Geoscience and Remote Sensing, 43(6), 1391-1402.

Wu, W., Zucca, C., Karam, F., Liu, G., 2016. Enhancing the performance of regional land cover mapping, International Journal of Applied Earth Observation and Geoinformation, 52, 422-432.

Yilmaz, M., Uysal, M., 2017. Comparing Uniform And Random Data Reduction Methods For DTM Accuracy, International Journal of Engineering and Geosciences (IJEG), Vol;2, Issue;01, pp. 9-16. 